\title{
Second-Look Endoscopy During Percutaneous Endoscopic Gastrostomy by Passing a Laryngofiber- scope Through the Inserted Feeding Tube
}

Percutaneous endoscopic gastrostomy (PEG) [1] has been widely accepted as a means of providing nutritional support for patients with head and neck cancer. Most techniques require a second-look gastroscopy to check that the feeding tube has been correctly positioned and to exclude complications [2], and many endoscopists carry these out. However peroral gastroscopy may be difficult in patients with large tumors or anatomical changes caused by surgery or irradiation. In addition, the procedure is unpleasant for the patient when it is done under local anesthesia, and also every pass of the gastroscope can increase the incidence of some procedure-related risks and complications, such as contamination of the feeding tube with oropharyngeal bacteria [3], and stomal tumor cell seeding $[4,5]$.

In order to minimize these problems, a laryngofiberscope (11003 BC; Karl Storz, Tuttlingen, Germany) was passed via the PEG feeding tube to obtain a second look, instead of a second peroral gastroscopy (Figure 1). To provide a greater deflection at the tip of the scope, a line was led through the instrument channel with one end fixed to the channel port and the other end brought back outside the instrument to the hand of the examiner. Thus the scope could be maneuvered using both the hand-piece of the instrument and the line, enabling the scope to be turned easily towards the internal disc of the PEG for a visual check. After traditional "pull-back" PEG with local anesthesia, we have kept the stomach insufflated, and in 12 instances we have passed the laryngofiberscope via the inserted feeding tube, after applying some lignocaine gel for lubrication. In all cases we were able to visualize the internal disc. This method avoids the discomfort for the patient of a second peroral gastroscopy, provides an alternative route for gastroscopy when the peroral approach is difficult, and reduces the possibility of some complications.

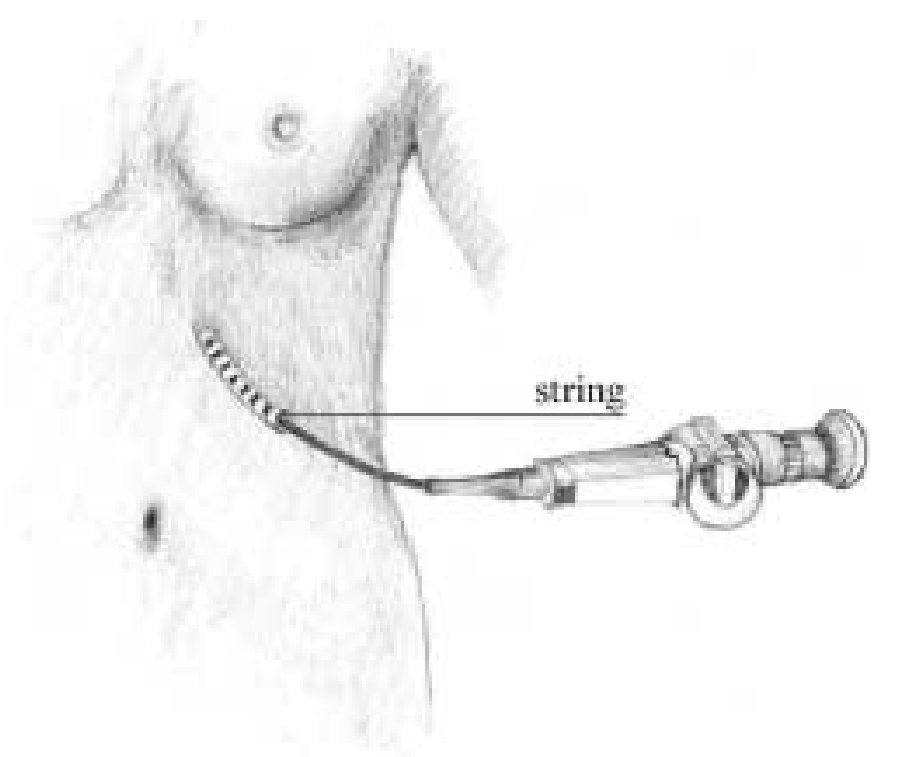

Figure 1 "Transtubal” endoscopy. A laryngofiberscope is passed through the percutaneous endoscopic gastrostomy (PEG) feeding tube. The instrument can be maneuvered by both the hand-piece of the scope and by the line attached to its tip.

\section{Lujber, J. Pytel}

Department of Otorhinolaryngology,

Faculty of Medicine, Pécs University, Pécs, Hungary.

\section{References}

${ }^{1}$ Gauderer MWL, Ponsky JL, Izant RJ. Gastrostomy without laparotomy. A percutaneous endoscopic technique. J Pediatr Surg 1980; 15: 872

2 Sacks BA, Vine HS, Palestrant AM et al. A nonoperative technique for establishment of a gastrostomy in the dog. Invest Radiol 1983; 18: 485 - 487

${ }^{3}$ Jain NK, Larson DE, Schroeder KW et al. Antibiotic prophylaxis for percutaneous endoscopic gastrostomy: a prospective, randomized double-blind clinical trial. Ann Intern Med 1987; 107: 824-828

${ }^{4}$ Laccoureye O, Chabardes E, MeriteDrancy A et al. Implantation metastasis following percutaneous endoscopic gastrostomy. J Laryngol Otol 1993; 107: 946-949

${ }^{5}$ Preyer S, Thull P. Gastric metastasis of squamous cell carcinoma of the head and neck after percutaneous endoscopic gastrostomy: report of a case. Endoscopy 1989; 21: 295

\section{Corresponding Author}

\section{Lujber, M.D.}

Tawam Hospital

PO Box 15258 Al-Ain

Abu Dhabi

United Arab Emirates

Fax: +971-3-7072133

E-mail: Lujber@hotmail.com 